\title{
Exploration of optical classroom teaching by network platform
}

Zheng Jiao, Kun Ma

Zheng Jiao, Kun Ma, "Exploration of optical classroom teaching by network platform," Proc. SPIE 10452, 14th Conference on Education and Training in Optics and Photonics: ETOP 2017, 104525H (16 August 2017); doi: 10.1117/12.2269750

SDIE Event: 14th Conference on Education and Training in Optics and Photonics, ETOP 2017, 2017, Hangzhou, China 


\title{
Exploration of Optical Classroom Teaching by Network Platform* JIAO Zheng, MA Kun School of Information Engineering, Huangshan University, Huangshan 245041, China
}

\begin{abstract}
The investigation shows that the difficulties students encounter in the course of optics are mainly due to the abstraction of the content of the optical course, and the problem that the description of the physical phenomenon and process is difficult to show in the classroom teaching. We consider to integrate information technology with classroom teaching. Teachers can set up course websites and create more teaching resources, such as videos of experimental processes, design of simulated optical paths, mock demonstration of optical phenomena, and so on.Teachers can use the courseware to link the resources of the website platform, and display the related resources to the students. After class, students are also able to learn through the website, which is helpful to their study.
\end{abstract}

KEYWORDS: optical course, dynamic graph, information technology, website, courseware,teaching resources, network platform, process

\section{INTRODUCTION}

The Optics course is a basic course for the students of the Optoelectronic Information Science and Engineering major. Many teachers have carried out in-depth research on the curriculum teaching.For example, Xu Jiawen ${ }^{[1]}$ gave recommendations for teaching by comparing the domestic and international teaching mode. Li Yijun et al. ${ }^{[2]}$ put forward their own views on the teaching content and teaching methods.Some scholars put forward the application of modern teaching methods in the course teaching to promote students' learning ${ }^{[3]}$. We conduct a survey of our students to know their understanding of the curriculum and their attitudes towards learning. We identify the factors that affect student learning, and find out the ways to improve the students' learning by setting up the website of the course, using the website to carry out the teaching and guiding the students to study.

\footnotetext{
*Author Email: jiaozheng@hsu. edu. cn
} 


\section{QUESTIONNAIRE SURVEY AND ANALYSIS}

In order to understand the learning situation of students' of Optics and discover the problems in teaching, we have conducted a questionnaire survey on the three grades of students in optoelectronic information science and engineering, involving a total of 224 students from grade2015, 2014 and 2013. We distributed 224 questionnaires, and 209 were recovered. The questionnaire is mainly from the following aspects: to understand students' interest in the course; to understand the reasons why students encounter difficulties in learning; to understand the expectations of students in modern teaching methods.

Through an analysis of the collected questionnaires, we focus on the summary from three aspects to understand the situation of students' learning.

\subsection{Overall situation}

We present the questionnaire on the overall situation of the curriculum listed in Table 1. The questionnaire asked students "Are you interested in optics?", "Do you think optics is important?", the two questions are to understand the students' understanding of the curriculum. The questionnaire asked "Is the teacher enough time to teach?", "Do you think positively in class?", "Can you keep up with the teacher 's progress during class?". We want to understand the students in the classroom lectures situation with these three problems. The questionnaire asked students whether they would review after class in order to understand the students' after-school review situation. We ask students to make a single choice of these questions from the three options: Yes, No, or Do not know.

Table 1 Students' Understanding of Curriculum

\begin{tabular}{llll}
\hline \multicolumn{1}{c}{ Question } & Yes & No & Don't know \\
\hline Are you interested in optics? & $86.6 \%$ & $1.3 \%$ & $12.1 \%$ \\
Do you think optical is important & $89.2 \%$ & $4.2 \%$ & $6.6 \%$ \\
Are the teaching hours enough? & $65.9 \%$ & $23.6 \%$ & $10.5 \%$ \\
Do you think positively in class? & $72.3 \%$ & $11.5 \%$ & $16.2 \%$ \\
Can you keep up with the teacher 's progress during class? & $64.8 \%$ & $32.3 \%$ & $2.9 \%$ \\
Will you review after class? & $93.3 \%$ & $6.7 \%$ & 0 \\
\hline
\end{tabular}

The choices of students tell us that they are very interested in the course. The importance of the course also has been understood. They are willing to think positively but sometimes they fell distressed, because they can not keep up with teacher, and content.

Proc. of SPIE Vol. $10452104525 \mathrm{H}-2$ 


\subsection{Factors affecting learning}

In the questionnaire, we set up several factors that affect students' learning, mainly to analyze the reasons students encounter difficulties in learning. Students make multiple choices. The results are shown in Figure1.

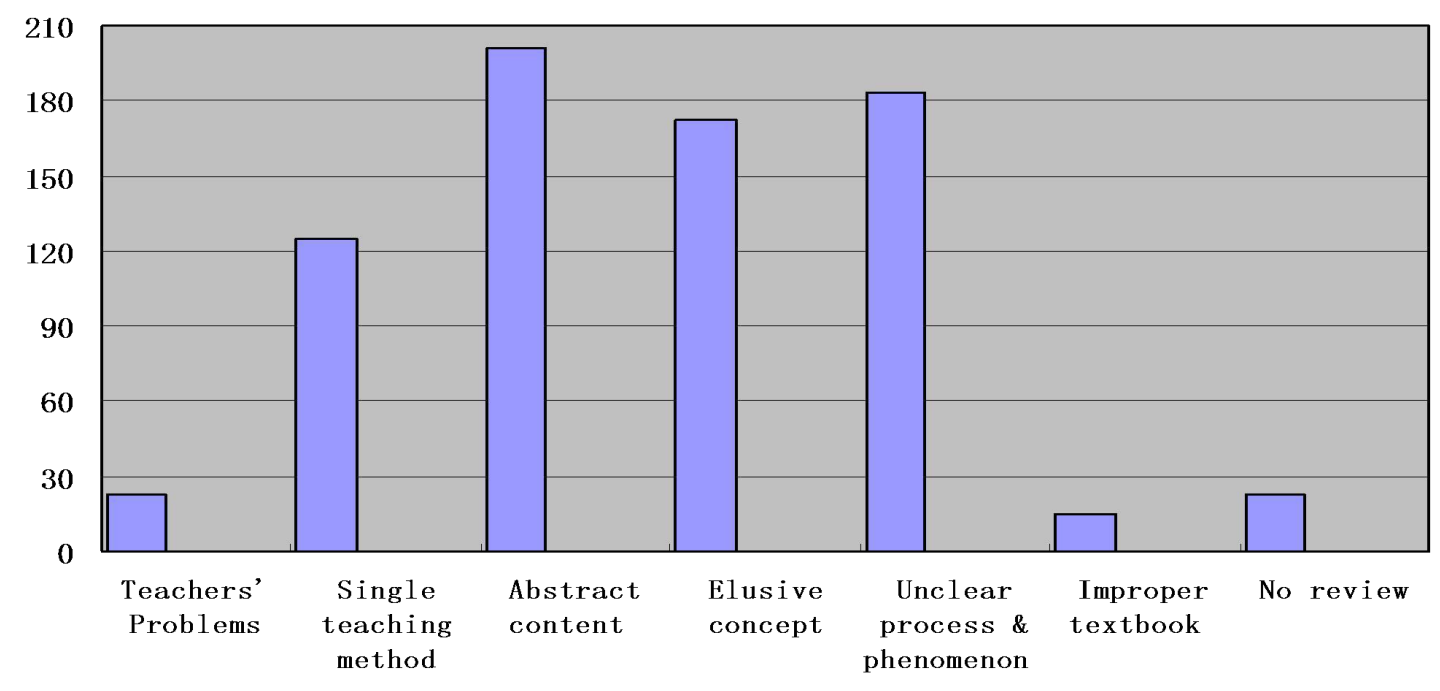

Figure 1. Factors Affecting Learning

The factors that affect the students' learning are mainly the abstraction of the optical content, and the students' difficulties in some processes and certain phenomena. There are few factors in terms of teachers' expression, teaching materials and hours. It confirms the students' willingness to think positively but keeping up with the teacher's progress is somewhat difficult because of the lack of understanding. Although more students are willing to review after class to make up for the lack of class time, the problem is worthy of our attention.

\subsection{Teaching methods expected}

In this regard, we have listed a number of teaching methods for students to choose, so that they can choose methods to promote learning teaching. The choices of students are shown in Figure 2.

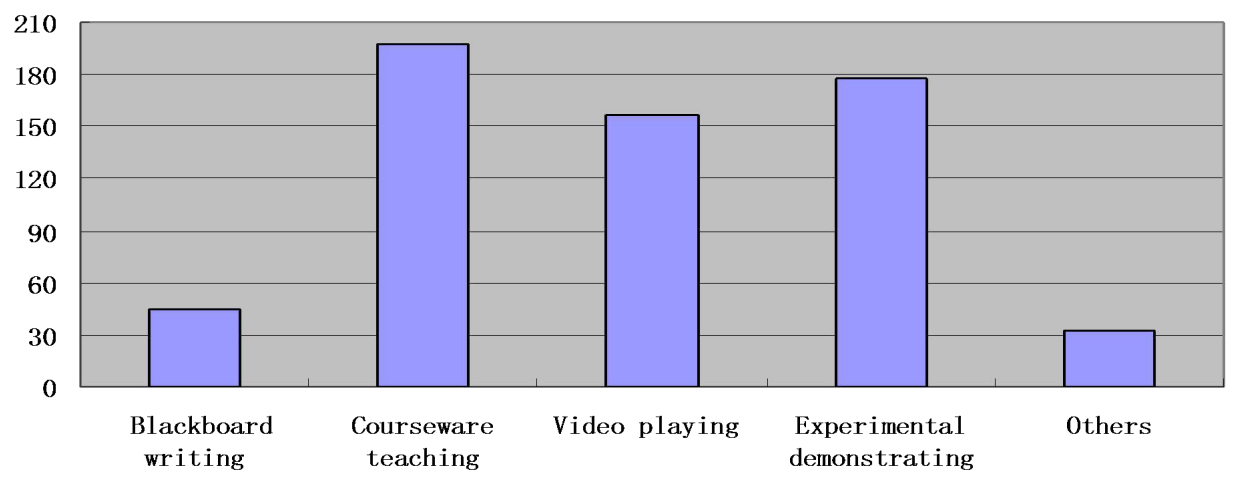

Figure 2. teaching methods

From the student's choice, we can know that students show little interest in the traditional blackboard teaching, they are inclined to teachers' using of multimedia teaching methods. Many students hope that the application of teaching 
courseware expands the amount of knowledge. They hope to promote understanding through video, teaching demonstration and other means.

\section{CREATING NETWORK TEACHING PLATFORM}

Now that there's no problem in the students' learning attitude, we can enhance the teaching effect based on the existing problemes. We can use the network platform for this work.

The network teaching platform not only contains more teaching resources but also provides students with interactive learning platform. We can try to use teaching courseware in class. When we are teaching with the multimedia courseware, we can link to the course site. We enter different areas of the site according to different course contents, such as experimental demonstration, the videos of principle, process simulation and other teaching methods which students have expected. The perfect combination of teaching site and classroom teaching can mobilize students' enthusiasm of listening to lectures.

\section{USING OF FLEXIBLE TEACHING METHODS}

In the process of classroom teaching, teachers can choose different modern teaching methods based on the established teaching platform. They can extract the teaching resources through courseware, according to the characteristics of the course content .

\subsection{Use diagrams to present principles and phenomena}

We illustrate abstract principles and phenomena by using the instructional resources which have been uploaded in the instructional website duing the courseware.

Take the "Huygens - Fresnel principle" as an example. When we explain the principle using language, it is not clear enough and will make students understand the deviation. This will further affect the subsequent study of students. We can extract the website resources in class to explain this principle of dynamic map and the principle of combining pictures(Figure 3).So that students will be able to master this principle.
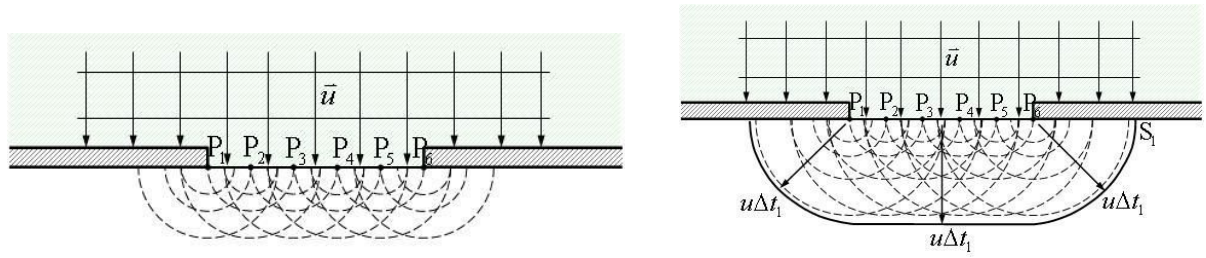

Figure 3. Huygens - Fresnel principle

\subsection{Use procedures to simulate physical processes}

In addition to the schematic diagram, we adopt different teaching methods for different problems. For example, we will encounter some problems due to changes in the conclusions when the parameters have been changed. For these problems, we can use MATLAB, ZEMAX and other software to write a simple program, it will be placed in the course website. During the course of teaching, the program can be invoked, and the students are clearly explained.

For example, when we talk about double-slit interference, although a formula can be used to calculate the relationship between the interference pattern with the distance of the double-slit $d$, the distance from the slit to the receiving screen $D$, and the wavelength $\lambda$, it is not intuitive. To solve this problem, we can use MATLAB to write a 
program. We change the physical quantities $d, D$ and $\lambda$ in class to get different interference patterns and light intensity distribution. We allow students to visually feel the brightness of stripes, stripe width and other changes when the separation distance and other parameters have been changed. (Figure 4-6) This is very helpful in explaining the characteristics that affect the double-slit interference fringes.

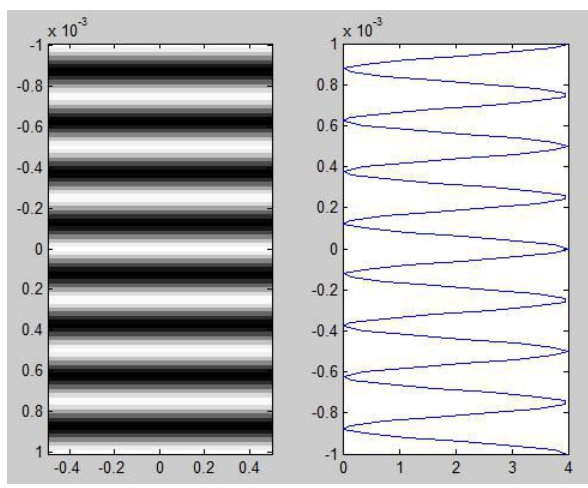

Figure 4a $d=2 \mathrm{~mm}$

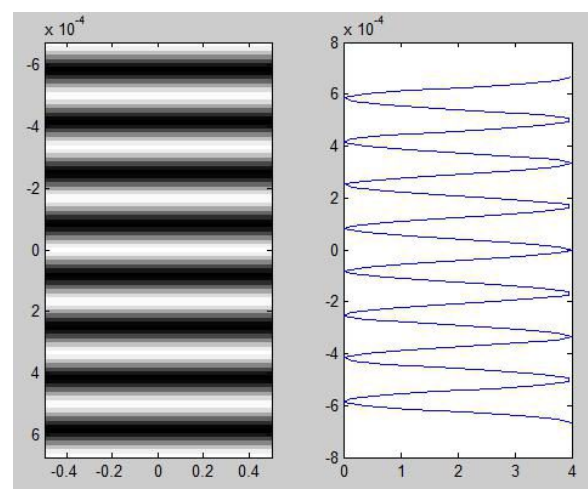

Figure $4 \mathrm{~b} \quad d=3 m m$

Figure $4 . \lambda=500 \mathrm{~nm}, D=1$, Change $d$
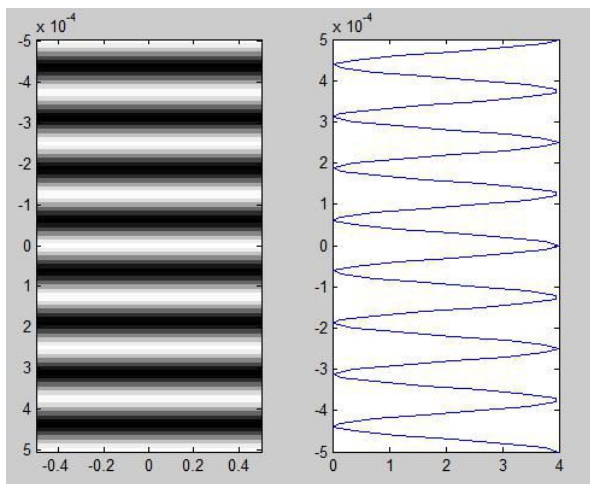

Figure $5 \mathrm{a} \quad D=1 \mathrm{~m}$

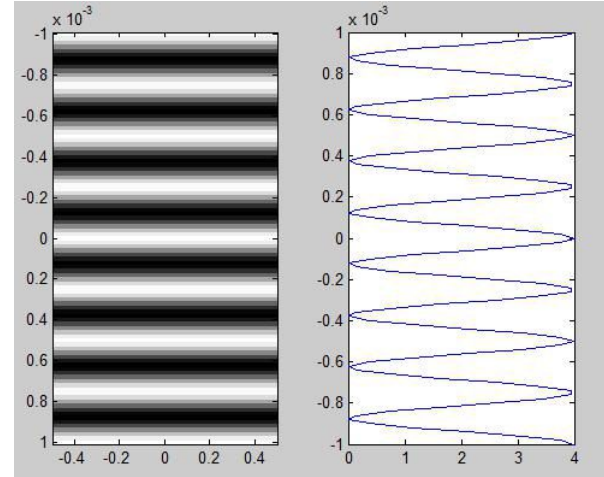

Figure $5 \mathrm{~b} \quad D=2 m$

Figure 5. $\lambda=500 \mathrm{~nm}, d=4 \mathrm{~mm}$, Change $D$
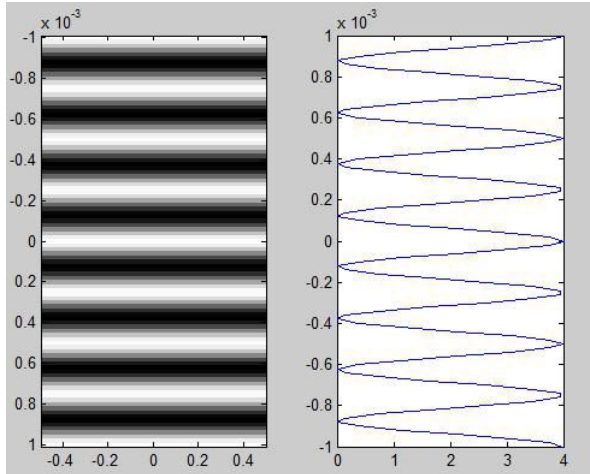

Figure $6 \mathrm{a} \lambda=500 \mathrm{~nm}$

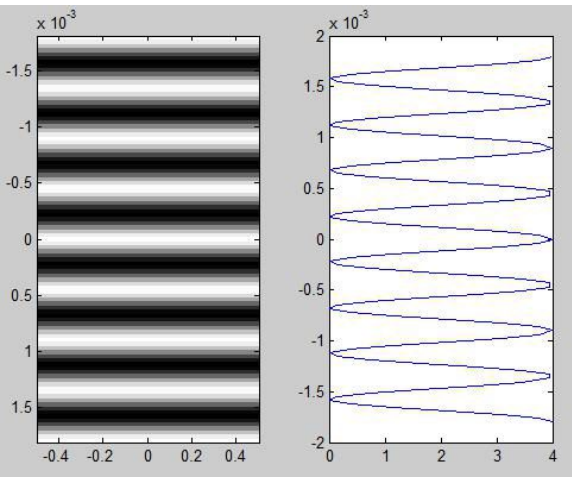

Figure $6 \mathrm{~b} \lambda=900 \mathrm{~nm}$

Figure 6. $d=2 m m, D=1 m$, Change $\lambda$ 
At present, the laser scanning system has been widely used in a variety of occasions, such as laser marking, laser etching, three-dimensional contour scanner, laser bar code scanners and so on. When it comes to the content of optical system design, it is difficult to grasp directly. We can use ZEMAX software to simulate in class. For example, when we need to explain the designing of a laser scanning system, we can use the program which has been prepared by the ZEMAX software in class, enter the following data in the ZEMAX lens editor:

\begin{tabular}{|c|c|c|c|c|c|c|c|c|c|}
\hline \multicolumn{9}{|c|}{ : Lens Data Editor: Config $1 / 5$} & \multirow[t]{2}{*}{$\square$ 回 $-x$} \\
\hline Edit & Solves View & Help & & & & & & & \\
\hline \multicolumn{2}{|c|}{ Surf: Type } & Conmunt & Radius & Thickness & Glass & Semi-Diameter & Conic & Par 0(unused) & Par 1(unus . \\
\hline OBJ & Standard & & Infinity & Infinity & & 0.000 & 0.000 & & \\
\hline STO & Standard & & Infinity & 100.000 & & 10.000 & 0.000 & & \\
\hline 2 & Coordinat.. & & & 0.000 & - & 0.000 & & & 0.0 \\
\hline 3 & Coordinat.. & Element Tilt & & 0.000 & - & 0.000 & & & 0.0 \\
\hline 4 & Standard & & Infinity & 0.000 & MIRROR & 12.208 & 0.000 & & \\
\hline 5 & Coordinat.. & Element Tilt & & 0.000 & - & 0.000 & & & 0.0 \\
\hline 6 & Coordinat. & & & -50.000 & - & 0.000 & & & 0.0 \\
\hline 7 & Standard & & 2017.456 V & -15.000 & BK7 & 28.766 & 0.000 & & \\
\hline 8 & Standard & & \begin{tabular}{ll|l}
79.889 & $F$
\end{tabular} & \begin{tabular}{ll|l|}
-155.149 & $\mathrm{v}$ \\
\end{tabular} & & 30.893 & 0.000 & & \\
\hline IMA & Standard & & Infinity & -1 & & 55.114 & 0.000 & & \\
\hline
\end{tabular}

Figure 7. lens editor

We can see the shadow map by shade model. Here are given five deflection angles which can be seen that different angles on the screen focus on different degrees (Figure8).
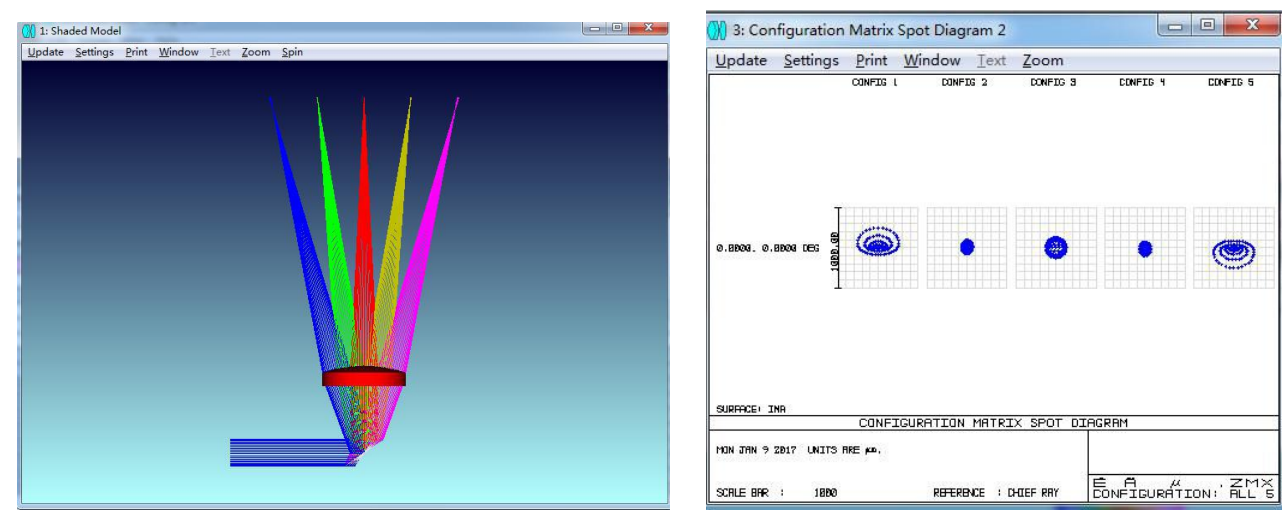

Figure 8. shadow map and Spot diagram

It is necessary to optimize the initial structure of the laser scanning system in order to focus each angle on the screen. The optimized shadow map is shown below. Specifically, we set the lens's radius of curvature as a variable, and the conic coefficient of the first face to -1. It can be optimized by the default evaluation tool in Merit Function. By optimizing we can see that there are many improvements in the degree of focusing on the screen at each angle, which can also be clearly seen from the dot plot below.(Figure9) 

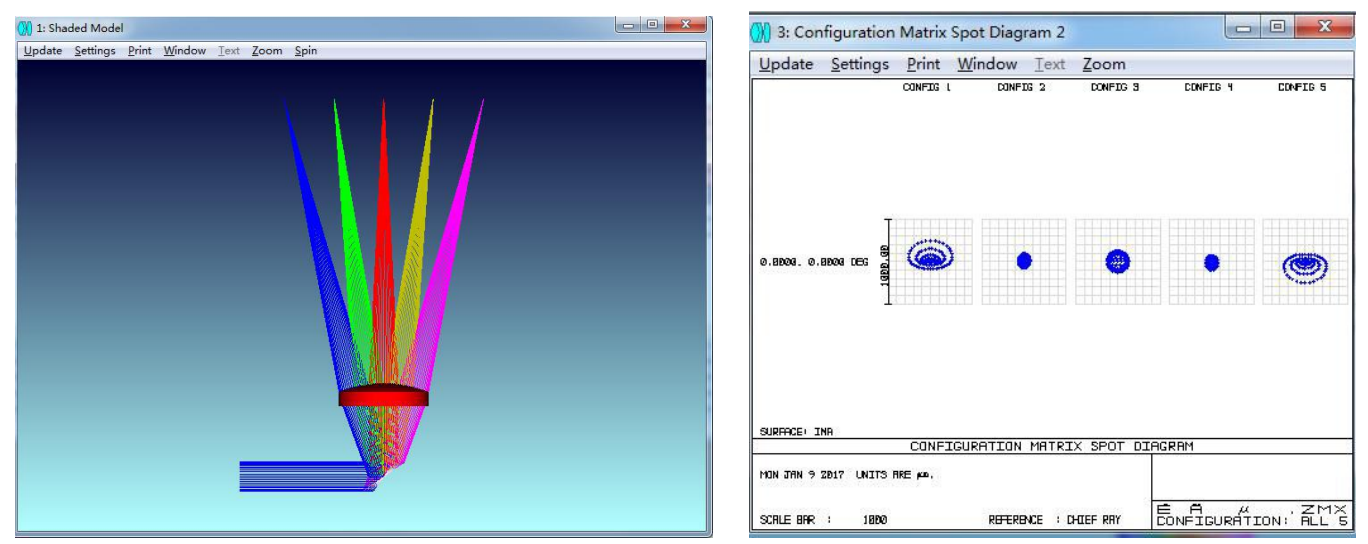

Figure 9. shadow map and Spot diagram

Through the demonstration of direct operation in class, students will be greatly improved.

\subsection{Explain the course content with the experimental video}

We can use videos to explain some of the knowledge. We have the corresponding experimental equipment in the laboratory but can not be carried out in the classroom. When teaching holograms, teachers can operate and take video recordings using a laboratory holographic device and play them in class. Students can visualize holographic conditions and show holographic images of network resources. They will be able to understand the problem of holography well.

\section{CONCLUSION}

Teachers establish a course website and use the web resources effectively for teaching.Students can solve a series of difficulties encountered in the optical study. After the establishment of the website, students can extend learning from in-class learning to after-class learning, to further improve their effect of optical learning and lay a solid foundation for further study of the professional courses.

\section{ACKNOWLEDGMENTS}

This work was supported by Revitalization Plan of Anhui Province (Grant No.2013zytz064), Anhui Province Key Teaching Research Project (Grant No.2016jyxm0974), Huangshan University Teaching Research Project (Grant No.2016JXYJ19), National Natural Science Foundation of China (Grant No. 11305074).

\section{REFERENCES}

[1] XU Jia - wen, "R eflection and practice about Teaching Modes of Applied Optics Course", Journal of Higher Education Research, Vol. 39(1), 115-120(2016).

[2]LI Yi-jun, "Research and Practice on the teaching reform of optics course in Colleges and Universities", Physics and Engineering, Vol. 23(5), 58-60(2013).

[3] Guo Jing, "Improve engineering optics teaching with modern teaching methods", China Modern Educational Equipment, 1, 57-59(2010). 